\title{
Optimizing the Design of an Inclined Subsoiler Using ANSYS
}

\author{
Saqib Parvaze Allaie ${ }^{1 *}$, Ashok Tripathi ${ }^{1}$, P. M. Dsouza ${ }^{1}$ and Sabah Parvaze $^{2}$ \\ ${ }^{1}$ Department of Farm Machinery and Power Engineering, VIAET, SHUATS, Prayagraj, India \\ ${ }^{2}$ College of Agricultural Engineering and Technology, SKUAST-K, \\ Jammu and Kashmir, India \\ *Corresponding author
}

\section{Keywords}

ANSYS, Inclined subsoiler, Structural analysis, Maximum safety factor

Article Info

Accepted:

24 August 2020

Available Online:

10 September 2020

\section{A B S T R A C T}

The present research was conducted for obtaining the optimized structural design of an inclined subsoiler with the help of ANSYS 17.0 software. The design software Solid Works was utilized for model creation using the data collected from the regional manufacturer. The structural analysis under the conditions of fixed boundary was performed in the ANSYS software. The result from the structural analysis revealed that the mass (P4) and volume (P9) of the subsoiler before optimization were $25.89 \mathrm{~kg}$ and $3289249.89 \mathrm{~mm}^{3}$. The maximum values for the total deformation (P5), equivalent stress (P6), principal stress (P7), and the minimum value for the safety factor (P8) were $2.7195 \mathrm{~mm}, 220.77 \mathrm{MPa}, 239.93 \mathrm{MPa}$ and 1.585 , respectively. Three parameters were considered for the optimization-thickness (P1), length of the curve (P2) and width of the shank (P3).Thereafter, the correlation of the output parameters with the input parameters was determined. It was observed that out of the three input parameters P1, P2, and P3, the correlation of $\mathrm{P} 1$ and $\mathrm{P} 3$ with the output parameters was high while the correlation of P2was low. Thus parameters, P1 and P3 were chosen for further analysis. Optimization was carried out with the goal being maximum safety factor and minimum subsoiler mass. The final optimized design was again modeled and its structural analysis done in ANSYS. The results post-optimization were compared against the results before optimization to find out the variations. It was found that after optimization, both P4 and P9 decreased by $18.72 \%$, P6, and $\mathrm{P} 7$ by $0.71 \%$ and $1.16 \%$, respectively while P5, P8, and maximum working life increased by $8.47 \%, 0.72 \%$, and $2.48 \%$ respectively. This reduction in mass is favorable as it reduced material use and also the input energy requirement during operation.

\section{Introduction}

Soil compaction is a serious problem in agricultural lands as it reduces the water absorption capacity of the soil and also resists root penetration thereby causing poor growth (Correa et al., 2019; Shah et al., 2017). For minimizing soil compaction, one of the major and most effective methods is the subsoiling operation. It is used for the elimination of the soil compaction to promote better water retention and crop growth (Akinci et al., 2004). Subsoiling is performed by the equipment called subsoiler. Subsoilers are 
attached to tractors and are pulled through the soil for breaking the hardpans. Subsoilers work deeper than normal tillage tools and therefore undergo huge resistance from the soil throughout their operation (Dransfield et al., 1964). The subsoiler structure must be able to withstand these forces, otherwise, it can deform and break during operation (Topakci et al., 2010). In order for the structure of the subsoiler to withstand the soil forces, it is vital that the different forces and their corresponding actions on the components of the subsoiler components be clearly identified. This data is crucial for the manufacturers and designers to take into consideration during the designing process.

Machine manufacturers, in order to prevent failures, make use of limited materials having high safety coefficients for the manufacturing process. Though it makes the equipment safe and reliable but leads to scaling up of production costs, equipment weight, and the overall energy input. A lot of designs can work satisfactorily under these conditions, but the primary objective is always to have an optimized design having a minimum cost and energy requirements and maximum safety. This makes the use of optimization methods important in this area (Rao, 2011).

The rapid advent of technology has led to the production of computers and software that can help designers in obtaining the solution to complex problems using computer-aided design (CAD) technologies and mathematical modeling without having to manufacture and test the machine in the physical world. The use of these technologies in machine design has been recorded since the early 1950s (Kureichik et al. 2019). Among these numerous techniques, the one that has become quite significant for problem-solving in engineering areas is the finite element method (FEM). It is used for obtaining approximate solutions to complex problems arising in the engineering design industry (Bhavikatti, 2005; Mahmoud, 1997). This method has also found its use in the agricultural sector where it is being used in the design and fabrication of agricultural machinery.

In the current study, optimization of the design of an inclined subsoiler has been performed by the ANSYS software. The objective of the study was to generate an optimum design with the minimum subsoiler mass and the maximum safety factor for the given field working conditions. The designing software Solid Works was used in the creation of the 3D models and the structural analysis and optimization carried out using the ANSYS software. Comparisons were done between the design before and after optimization for determining the improvements.

\section{Materials and Methods}

The different dimensions of the subsoiler were collected from the regional manufacturer and were used for creating the 3D model in the Solid Works software (Figure.1). The parameters whose optimizing was to be performed were given different names starting with "DS" for use in ANSYS as ANSYS recognizes dimensions with certain prefixes only. Once the modeling process was complete, static structural analysis using the FEM approach was setup in ANSYS.

The static structural analysis was used for determining the force and the resulting stresses and strains on the subsoiler shank. The response conditions were assumed under steady loading conditions. The 3D geometry was attached to the structural analysis and the engineering properties applied. The material chosen for the subsoiler was hot-rolled structural steel in accordance with IS:2062E250, 2011. 
The material definition was succeeded by the meshing step. The meshing tool of the ANSYS software (Zhang and Ju, 2008) was used for creating a fine mesh of $5 \mathrm{~mm}$ (Figure.2). The meshing process is used for discretizing the geometry into smaller components consisting of elements and nodes. Right after the meshing process, the boundary conditions were set. The first condition was the holes in the subsoiler frame used for attaching the subsoiler to its frame (Figure.3). The second condition was the force acting on the blade of the subsoiler (Figure.4). A force of $7288 \mathrm{~N}$ (Yadav, 2014) was applied on the blade. After the conditions were set up, the solving process was initiated, and the results obtained. The input parameters and the results obtained were then exported into a parametric set for use in correlation analysis during optimization.

Optimization is defined as obtaining the solution for one variable that acts as a constraint for a set of variables that are the minimized functions of an objective function (Topakci et al., 2010). The problems on structural optimization can be classified according to the kind of structure, design, and behavior (Srivastava et al., 2017). The problems on structural optimization are generally grouped based on the topology, size, and shape. The size optimization was considered in the present study with the goal being a minimum subsoiler mass but maximum safety. The optimization was limited only to the three parameters-P1, P2, and $\mathrm{P} 3$. The initial values of these parameters were $25 \mathrm{~mm}, 120 \mathrm{~mm}$ and $90 \mathrm{~mm}$, respectively. The design constraints for these parameters were as follows:

$\mathrm{P} 1: 20 \mathrm{~mm} \leq \mathrm{P} 1 \leq 25 \mathrm{~mm}$

$\mathrm{P} 2: 110 \mathrm{~mm} \leq \mathrm{P} 2 \leq 130 \mathrm{~mm}$

P3: $80 \mathrm{~mm} \leq \mathrm{P} 3 \leq 100 \mathrm{~mm}$
The ANSYS optimization tool "DesignXplorer" was used for carrying out the optimization process. The first step in the process is the parametric correlation. The parametric correlation is used to obtain the degree of relationship among the input and output parameters (Meshing, 2010). The Pearson correlation analysis was used for establishing the correlation and a group of 100 samples was obtained. The correlation results were used for determining the input parameters for use in further analysis. These parameters were used for the design set generation for the given conditions. The design sets were further used in the optimization process for obtaining the optimum design. A total of 1000 design sets were produced and arranged according to the objective of having a maximum safety factor and minimum mass. The design point that best fits the design goal was filtered. The design parameters of the optimized design were again used for creating the 3D model of the optimized subsoiler. Structural analysis was performed on the optimized subsoiler and the results compared with that of the original design to draw out the conclusions.

\section{Results and Discussion}

3D solid model of the subsoiler was created and imported into the ANSYS software and the meshing carried out. The meshing process resulted in the creation of 55243 nodes and 29658 elements. The results from the solver showed that for the given conditions the values for the parameters P3, P4,P5, P6, P7, $\mathrm{P} 8$, and P9 were $25.89 \mathrm{~kg}, 2.7195 \mathrm{~mm}, 220.77$ $\mathrm{MPa}, 239.93 \mathrm{MPa}, 1.585$ and 3289249.89 $\mathrm{mm}^{3}$, respectively (Figure.5). The stresses on the subsoiler were below the yield point of the material and there was minimal deformation (Table 1).

Optimization was thereafter applied to check if an alternate design with lower solid mass 
could be obtained while keeping the safety factor maximum at the same time. The first step of the optimization process was the parametric correlation. The results from the parametric correlation are shown in Table.2.

The parameter P1 had the best correlation with P4, P5, and P9. The parameter P2 had a very poor correlation with all the output parameters. The parameter P3 had a good correlation with $\mathrm{P} 5, \mathrm{P} 6, \mathrm{P} 7$, and $\mathrm{P} 8$. Therefore, P1 and P3 were considered for further analysis and parameter P2 was not used further in the process.
The completion of the correlation process was followed by the design set generation. The design points were used for the optimization process for tradeoff chart generation and for obtaining the candidate points. The tradeoff charts present the change in each output parameters with changes in the input parameters. The tradeoff charts are shown in Figure 6. A total of 1000 sample points were obtained for the target design. The points have varying colors where green color represents the most feasible point and the gray the infeasible ones.

Table.1 Material properties of hot-rolled structural steel

\begin{tabular}{|c|l|l|l|}
\hline S. No. & \multicolumn{1}{|c|}{ Material Properties } & \multicolumn{1}{|c|}{ Value } & \multicolumn{1}{c|}{ Units } \\
\hline $\mathbf{1}$ & Density & 7.87 & $\mathrm{~g} / \mathrm{cc}$ \\
\hline $\mathbf{2}$ & Poisson Ratio & 0.29 & \\
\hline $\mathbf{3}$ & Young's Modulus & 205000.00 & $\mathrm{MPa}$ \\
\hline $\mathbf{4}$ & Tensile Ultimate Strength & 420.00 & $\mathrm{MPa}$ \\
\hline $\mathbf{5}$ & Yield Strength & 350.00 & $\mathrm{MPa}$ \\
\hline
\end{tabular}

Table.2 Correlation between the input and output parameters

\begin{tabular}{|c|c|c|c|c|r|c|}
\hline Parameters & P4 & P5 & P6 & P7 & P8 & \multicolumn{1}{|c|}{ P9 } \\
\hline P1 & $\mathbf{0 . 8 8 4 9 0 7}$ & $\mathbf{- 0 . 6 1 6 0 1}$ & -0.38672 & -0.41285 & 0.36885 & $\mathbf{0 . 8 8 4 9 0 7}$ \\
\hline P2 & -0.00349 & -0.00889 & -0.04721 & -0.10749 & 0.053797 & -0.00349 \\
\hline P3 & 0.472416 & $\mathbf{- 0 . 7 8 9 9 8}$ & $\mathbf{- 0 . 6 7 9 4 9}$ & $\mathbf{- 0 . 8 2 6 2 8}$ & $\mathbf{0 . 7 3 0 5 5 1}$ & 0.472416 \\
\hline
\end{tabular}

Table.3 Design parameters of the optimized subsoiler

\begin{tabular}{|c|l|r|}
\hline S. No. & \multicolumn{1}{|c|}{ Parameter } & \multicolumn{1}{|c|}{ Value } \\
\hline $\mathbf{1}$ & P1 - Thickness of Shank $(\mathrm{mm})$ & 20.32 \\
\hline $\mathbf{2}$ & P2 - Width of Shank $(\mathrm{mm})$ & 99.70 \\
\hline $\mathbf{3}$ & P4 - Inclined Subsoiler Mass $(\mathrm{kg})$ & 22.657 \\
\hline
\end{tabular}


Figure.1 Different views and dimensions of the inclined subsoiler

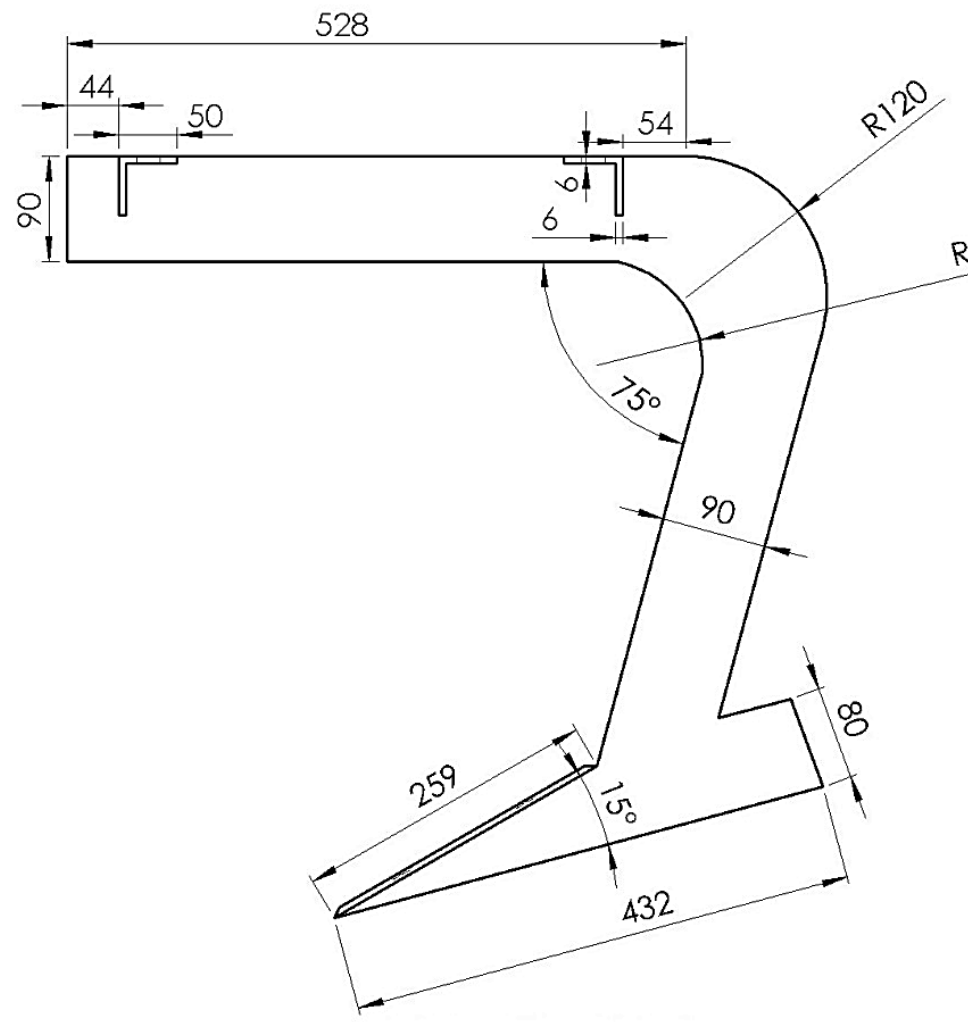

RIGHT SIDE VIEW

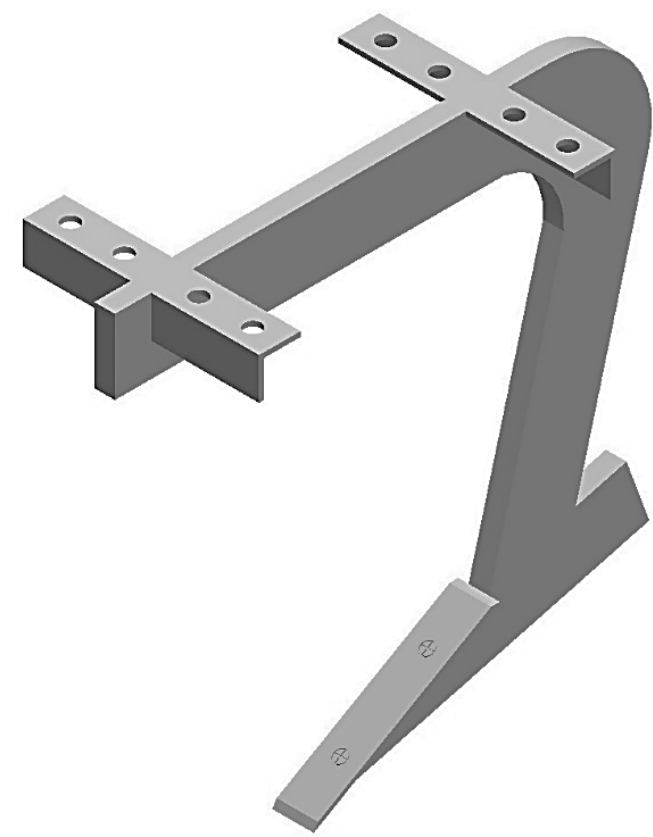

ISOMETRIC VIEW

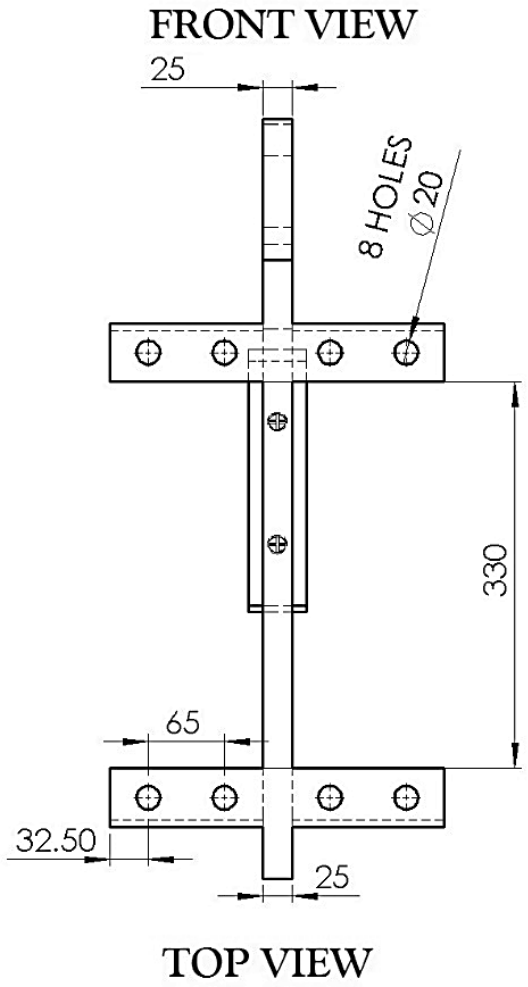


Figure.2 Meshed inclined subsoiler

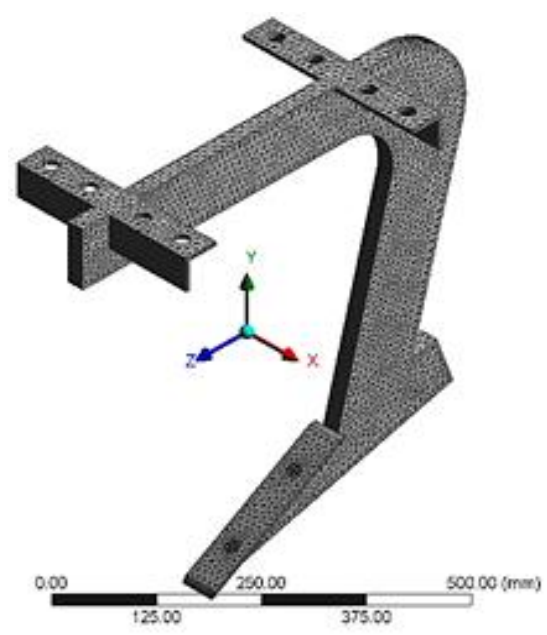

Figure.3 Boundary condition 1: Fixed supports

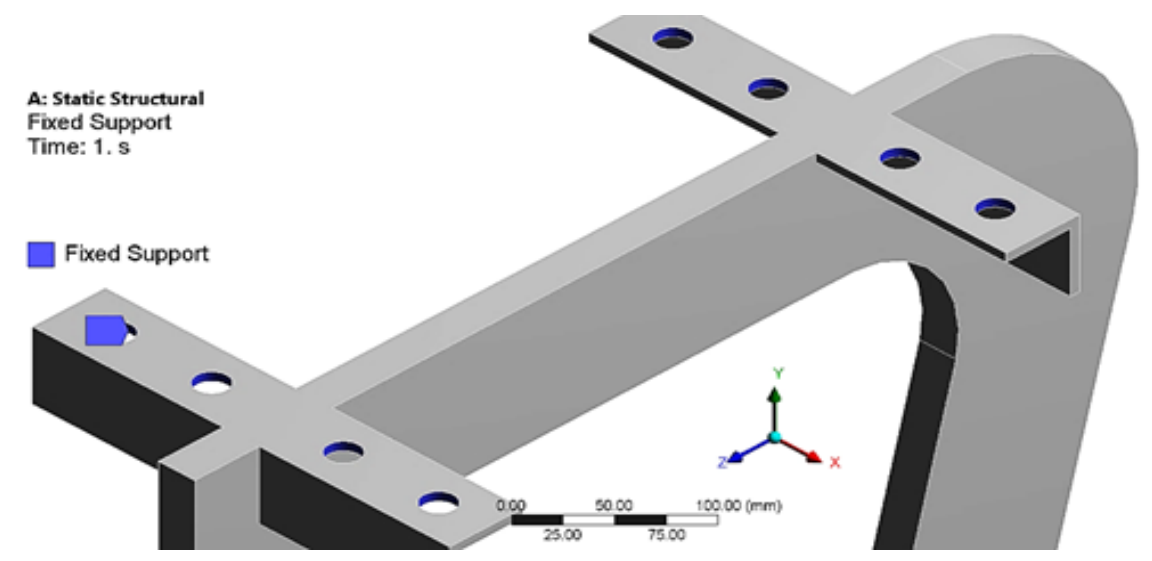

Figure.4 Boundary condition 2: Force on blade

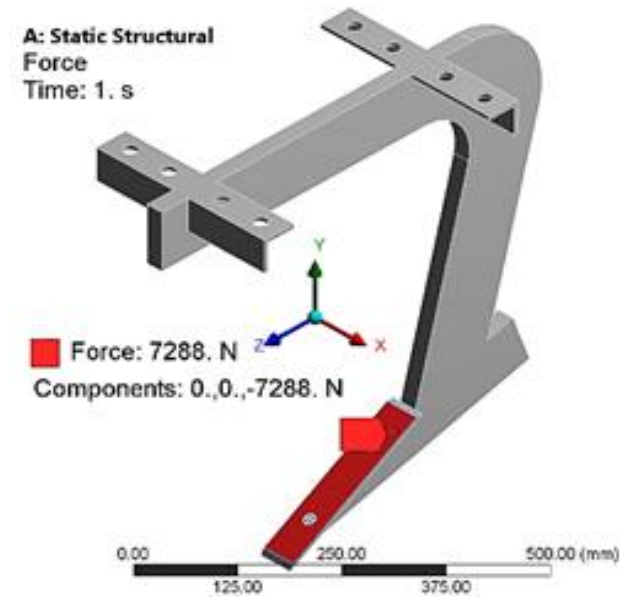


Figure.5 Total Deformation, Equivalent Stress, Maximum Principal Stress and Safety factor for the initial subsoiler design
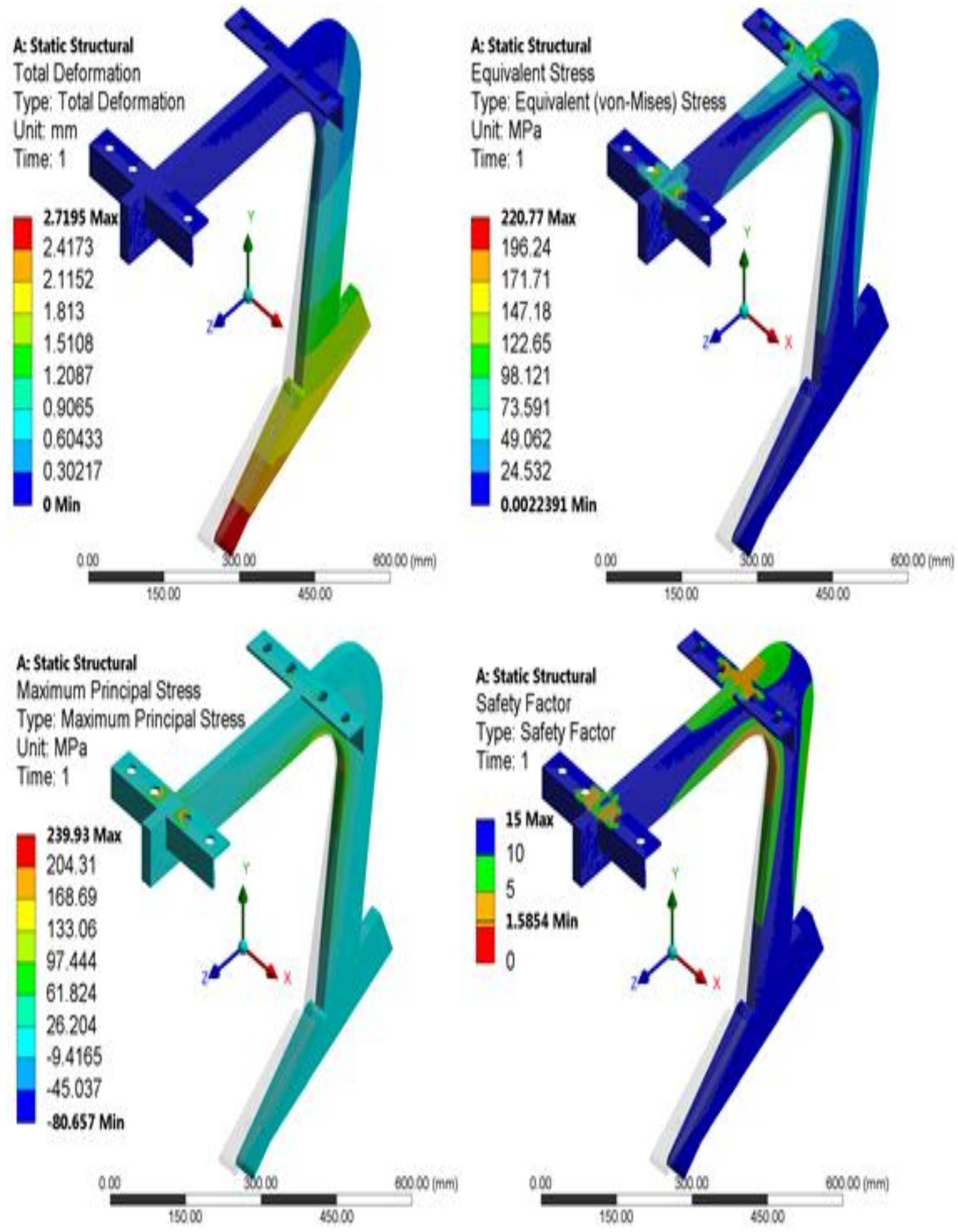
Figure.6 Tradeoff charts of the output parameters
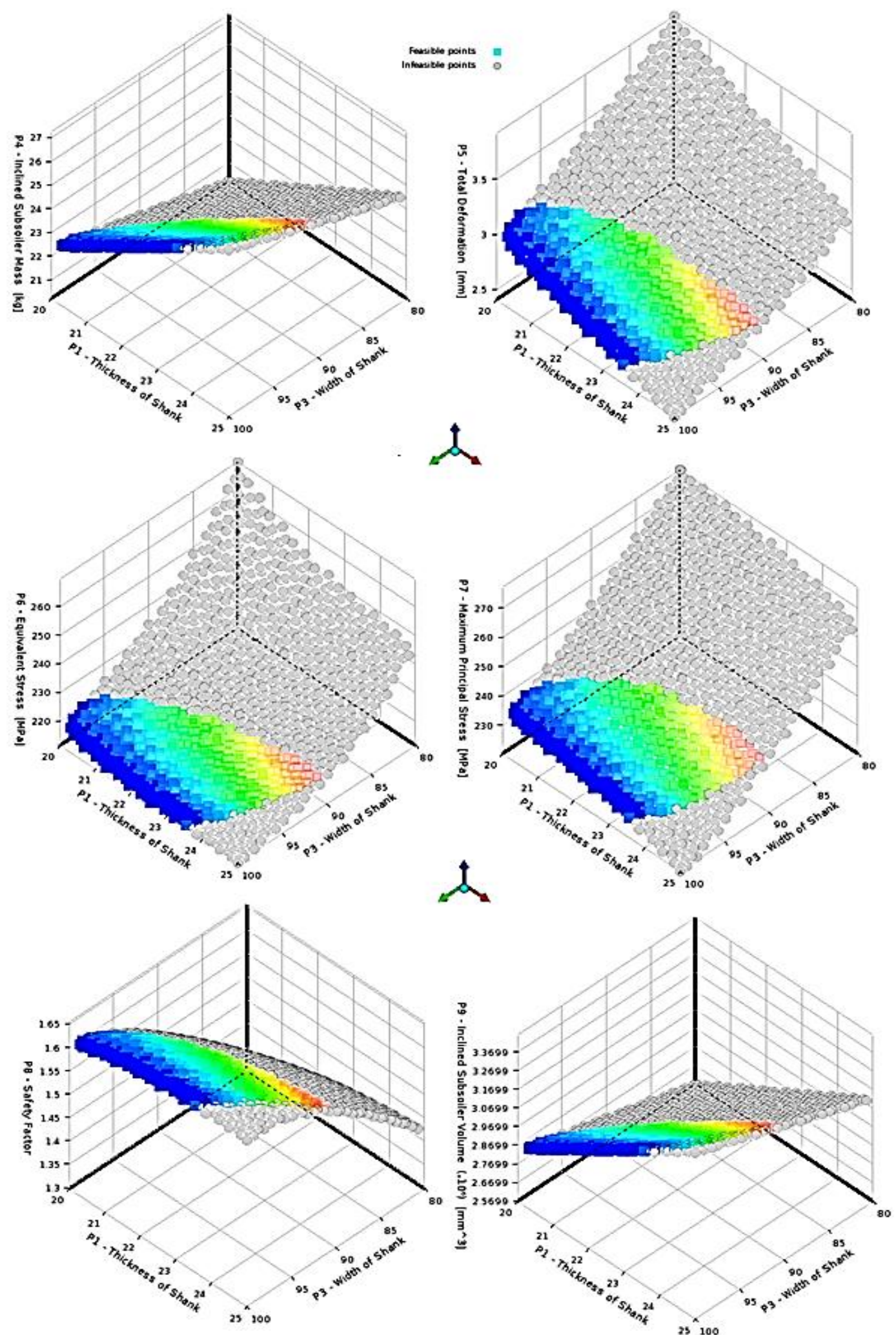
Figure.7 Candidate design points obtained from the optimization process

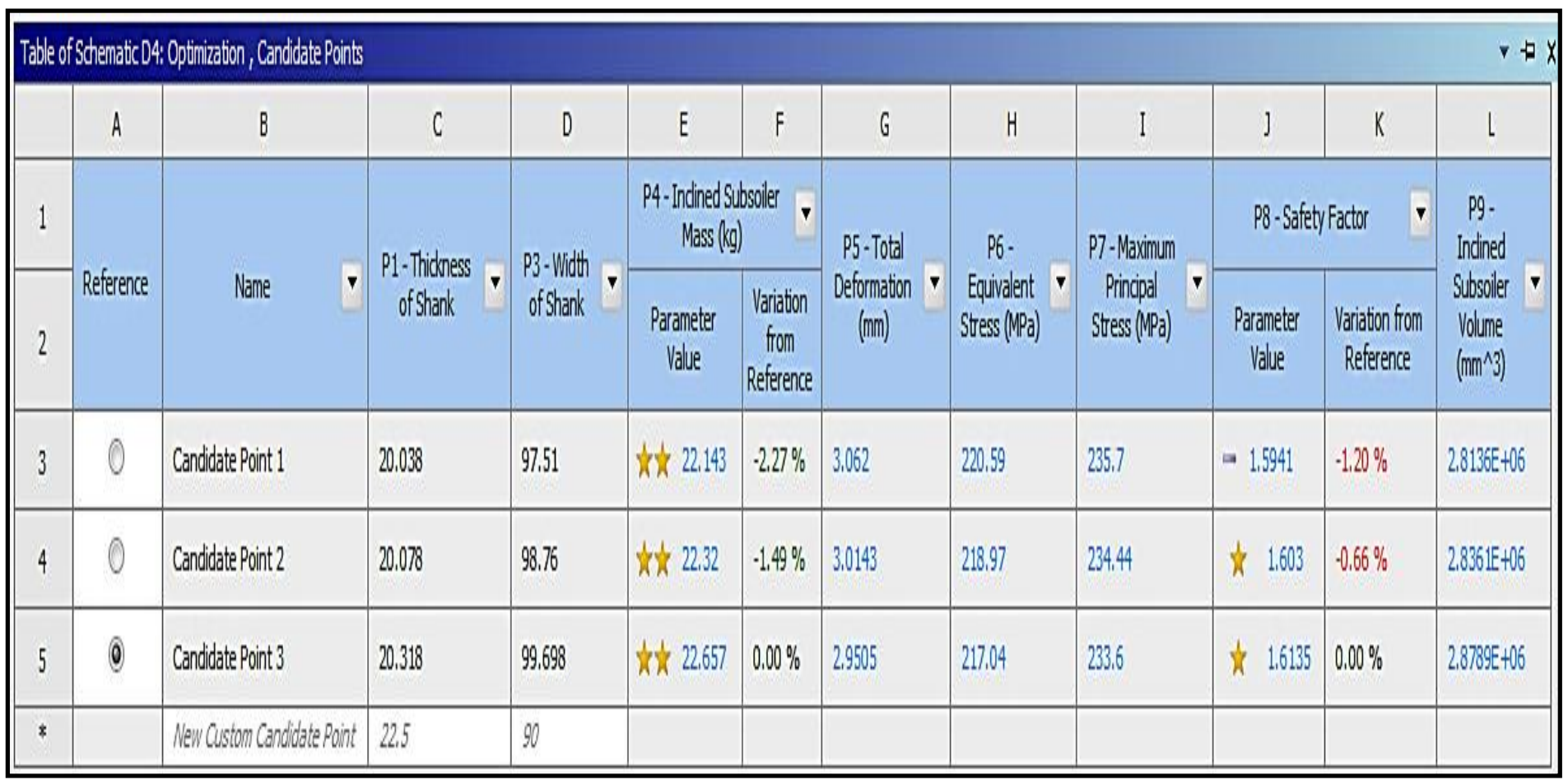


Figure.8 Design parameters of the optimized subsoiler

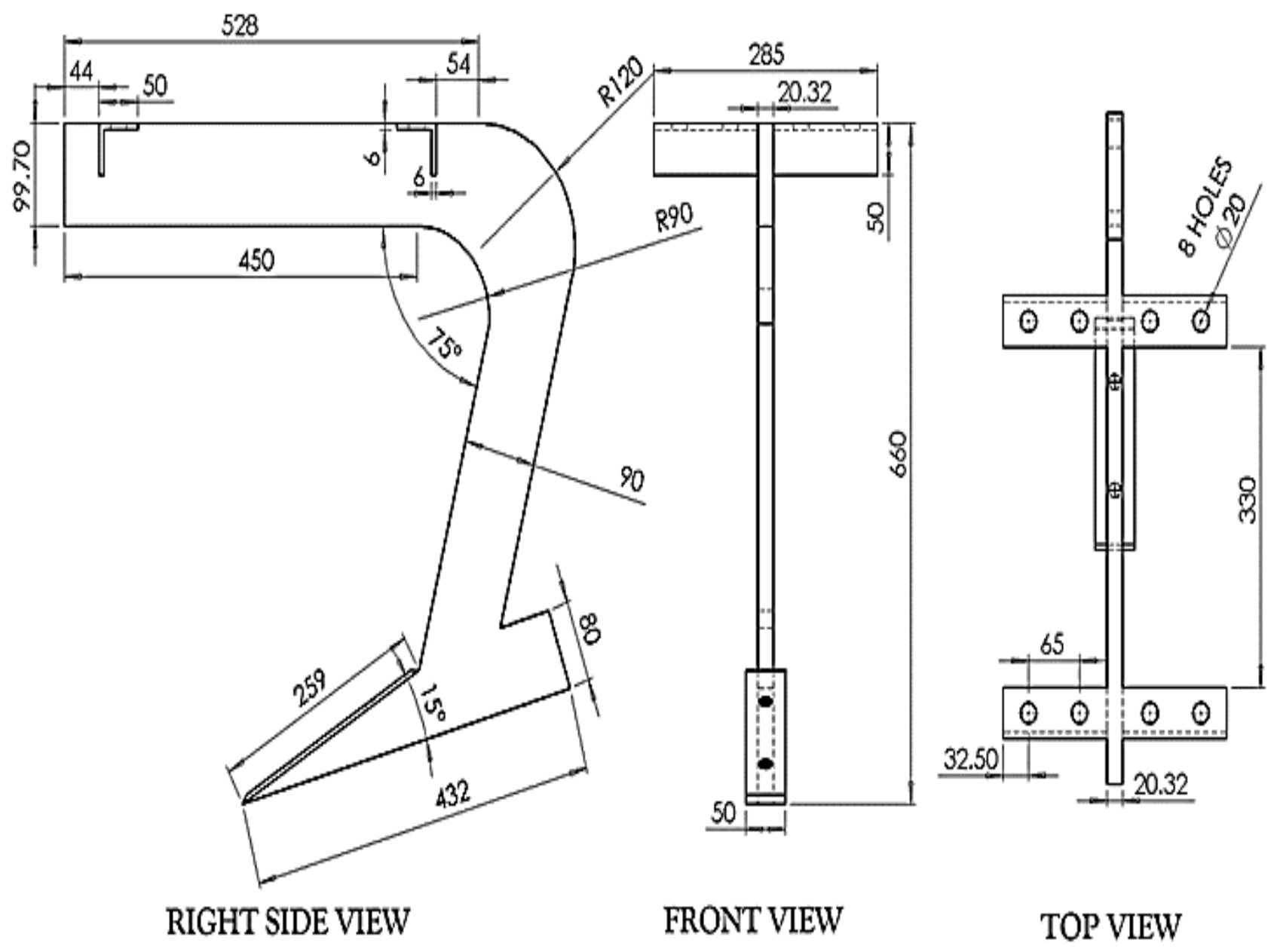


Figure.9 Variation of output parameters of the final model from the initial model

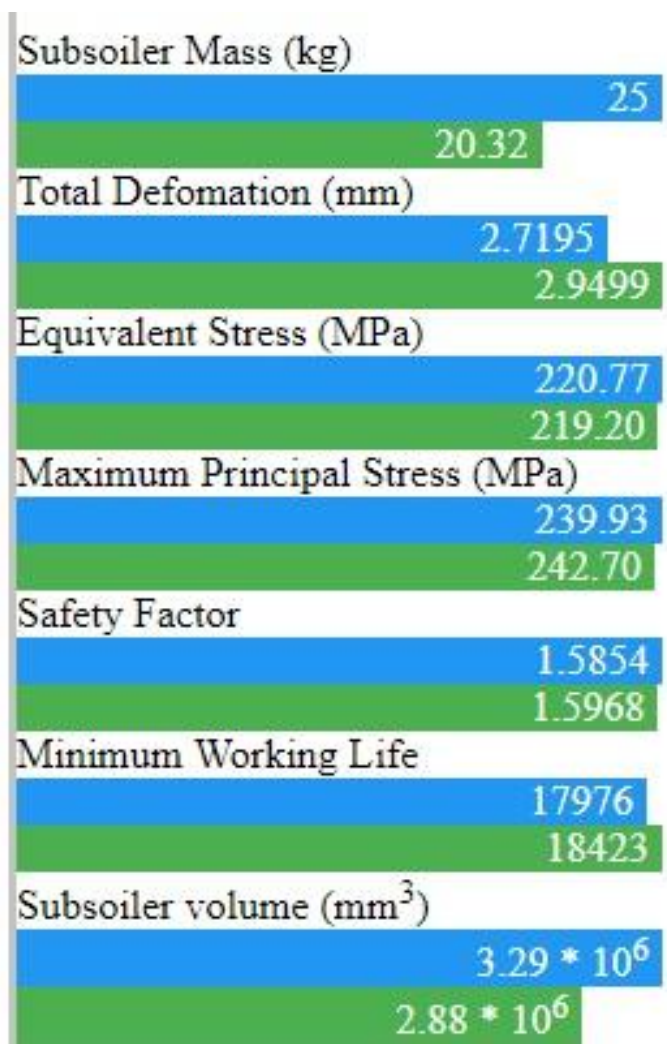

The analysis of the tradeoff charts showed that the minimum value for the safety factor was 1.5855 and was greater than that found in the original design. The subsoiler mass at this point was found to be $23.45 \mathrm{~kg}$, which was again lower than the original mass of 25.89 $\mathrm{kg}$. Therefore, for the given safety factor, the initial design had $2.44 \mathrm{~kg}$ of excess mass. An alternate design was also found with a safety factor of 1.61 and a mass of $22.66 \mathrm{~kg}$. This design had the lowestmass. The candidate points were thereafter generated for obtaining different designs for the given objectives. The candidate points obtained after the completion of the optimization process are shown in Figure.7. The ANSYS software outputs the three most relevant candidate points and each candidate point is presented along with the different input and output parameters. The data of these 3 points were checked for suitability control for agreement with the operating conditions and the best one filtered out. The design parameters of the optimized design are given in table. 3 and the final model is shown in Figure.8.

The structural analysis of the final model was again performed and the change of the final model parameters as compared to the initial model determined. The variation of the final model from the original model is shown in Figure.9. It was found that after optimization, both P4 and P9 decreased by $18.72 \%$, P6, and P7 by $0.71 \%$ and $1.16 \%$, respectively while P5, P8, and maximum working life increased by $8.47 \%, 0.72 \%$, and $2.48 \%$ respectively

The present research was undertaken for obtaining an optimized design of an inclined subsoiler with the help of ANSYS 17.0 software. The 3D model of the subsoiler was created in SolidWorks and then imported, 
analyzed and optimized using the different tools in ANSYS Software. From the study, the following conclusions could be drawn:

The meshing process resulted in the creation of 55243 nodes and 29658 elements.

The results from the solver showed that for the given conditions the values for the parameters P3, P4, P5, P6, P7, P8, and P9 were $25.89 \mathrm{~kg}, 2.7195 \mathrm{~mm}, 220.77 \mathrm{MPa}$, $239.93 \mathrm{MPa}, 1.585$ and $3289249.89 \mathrm{~mm}^{3}$, respectively.

The stresses on the subsoiler were below the yield point of the material and there was minimal deformation.

The parameter $\mathrm{P} 1$ had the best correlation with P4, P5, and P9. The parameter P2 had a very poor correlation with all the output parameters. The parameter P3 had a good correlation with $\mathrm{P} 5, \mathrm{P} 6, \mathrm{P} 7$, and $\mathrm{P} 8$.

Optimization of the inclined subsoiler reduced both the subsoiler mass and volume by $12.47 \%$. The maximum equivalent stress and principal stress were reduced by $0.71 \%$ and $1.16 \%$, respectively while the total deformation, the minimum factor of safety and maximum working life were increased by $8.47 \%, 0.72 \%$ and $2.48 \%$, respectively.

This reduction in the mass and volume of the subsoiler is favorable both in terms of reducing the production cost due to less material usage and lesser energy input for operation due to the lower weight of the subsoiler

\section{References}

Akinci, I., Cakir, E., Topakci, M., Canakci, M., Inan, O., 2004. The effect of subsoiling on soil resistance and cotton yield. Soil Tillage Res.
Bhavikatti, S.S., 2005. Finite element analysis, New age international (P) Limited, Publishers.

Correa, J., Postma, J.A., Watt, M., Wojciechowski, T., 2019. Soil compaction and the architectural plasticity of root systems. J. Exp. Bot.

Dransfield, P., Willatt, S.T., Willis, A.H., 1964. Soil-to-implement reaction experienced with simple tines at various angles of attack. J Agric Engng Res 9, 220-224.

IS:2062-E250, 2011. Hot rolled medium and high tensile structural steel Specifications.

Kureichik, V., Bova, V., Kureichik, V., 2019. Hybryd Approach for Computer-Aided Design Problems. In: 2019 International Seminar on Electron Devices Design and Production, SED 2019 Proceedings. Institute of Electrical and Electronics Engineers Inc.

Mahmoud, K.G., 1997. An efficient approach to structural optimization. Comput. Struct. 64, 97-112.

Meshing, S., 2010. Introduction to ANSYS Meshing. Workbench.

Rao, R.V., 2011. Advanced Modeling and Optimization of Manufacturing Processes, Springer.

Shah, A.N., Tanveer, M., Shahzad, B., Yang, G., Fahad, S., Ali, S., Bukhari, M.A., Tung, S.A., Hafeez, A., Souliyanonh, B., 2017. Soil compaction effects on soil health and cropproductivity: an overview. Environ. Sci. Pollut. Res. 24, 10056-10067.

Srivastava, P.K., Simant, Shukl, S., 2017. Structural Optimization Methods: A General Review. Int. J. Innov. Res. Sci. Eng. Technol. 6, 88-92.

Topakci, M., Celik, H.K., Canakci, M., Rennie, A.E.W., Akinci, I., Karayel, D., 2010. Deep tillage tool optimization by means of finite element method: Case study for a subsoiler tine. J. Food, 
Agric. Environ.

Yadav, M. V., 2014. Force and pressure distribution on selected tillage machinery. analysis based on ProE, HyperMesh and ANSYS. In: Proceedings - International Conference on Computer Science and Software Engineering, CSSE 2008.

Zhang, R., Ju, J., 2008. Finite element

\section{How to cite this article:}

Saqib Parvaze Allaie, Ashok Tripathi, P. M. Dsouza and Sabah Parvaze. 2020. Optimizing the Design of an Inclined Subsoiler Using ANSYS. Int.J.Curr.Microbiol.App.Sci. 9(09): 36263638. doi: https://doi.org/10.20546/ijcmas.2020.909.448 